\title{
ORIENTACIONES JURISPRUDENCIALES SOBRE LA MOTIVACIÓN DE LA SENTENCIA EN EL PROCEDIMIENTO MONITORIO
}

\author{
Álvaro Domínguez MONTOYA* \\ Universidad de Concepción
}

\section{INTRODUCCIÓN}

El objetivo del presente trabajo es tratar la impugnabilidad de las sentencias dictadas en este tipo de procedimiento y, en particular, a los requisitos que debe cumplir el sentenciador al fallar un asunto puesto en su conocimiento, así como la situación producida por la omisión de la motivación y su repercusión a la hora de interponer el Recurso de Nulidad.

\section{LAS SENTENCIAS DICTADAS EN EL PROCEDIMIENTO MONITORIO Y SU IMPOSIBILIDAD LEGAL DE IMPUGNABILIDAD}

La legislación laboral contempla diversos procesos para atender o cautelar los intereses que existen en la relación jurídica laboral, distinguiendo, a su vez, para cada uno de estos una serie de requisitos a cumplir cuando el juez falla un asunto puesto en su conocimiento. Así, la sentencia dictada en el procedimiento de aplicación general debe cumplir con los requisitos del art. $459^{1}$, la del procedimiento de tutela con los requisitos del art. 495 y, finalmente, la del procedimiento monitorio con los requisitos del art. 501 del Código del Trabajo. Formalmente, estas exigencias son las de mayor relevancia en cuanto representan ciertos deberes a los que debe atenerse el sentenciador, ya que serán aquellas las que determinarán, en último término, las normas procesales y sustanciales infringidas y fundantes de un posterior recurso en contra del fallo. De esta forma, cobra relieve el requisito que hace mención a la motivación y fundamentación de la sentencia.

Lo anterior se refuerza al analizar la facultad de los jueces laborales de apreciar la prueba de acuerdo con las reglas de la sana crítica. Entonces, queda en evidencia el íntimo e indisoluble vínculo existente entre la motivación de las sentencias y el sistema de valoración de la prueba que informa al renovado sistema procesal laboral chileno. Asimismo, la innega-

\footnotetext{
* Alumno ayudante del Departamento de Derecho Laboral y Seguridad Social de la Escuela de Derecho, Facultad de Ciencias Jurídicas y Sociales de la Universidad de Concepción. Contacto: adominguez@udec.cl

${ }^{1}$ Lo destacable en los requisitos contemplados en el articulo 459, es que no solamente se hace mención a la ley como fuente formal, sino que señala y da el mismo nivel de validez a "los preceptos constitucionales, legales o los contenidos en tratados internacionales ratificados por Chile y que se encuentren vigentes, las consideraciones jurídicas y los principios de derecho o de equidad en que el fallo se funda". Cuestión que desde ya no es menor, en consideración a que los principios, en razón de su naturaleza y su función, gozan de aquella ductibilidad y capacidad que carecen otras fuentes formales. Tal característica reviste una mayor importancia en el Derecho del Trabajo, ya que: "son los principios los que puedan dar consistencia, firmeza, seguridad a la lucha por mantener y fecundar el derecho del trabajo". PLÁ RODRfGUEZ, Américo, "Presencia actual de los principios del Derecho del Trabajo en América Latina", en: Revista Laboral Chilena, p. 8.
} 
ble relación con las causales de nulidad contempladas en el artículo 478 b) y e) del CT. En cuanto a esto último y respecto de una sentencia definitiva dictada en un procedimiento monitorio, la jurisprudencia ha seńalado una imposibilidad natural de conocimiento de un recurso de nulidad fundado en la causal b) del artículo 478 del $\mathrm{CT}^{2}$, por carecer en su modelo legislativo o, más bien, por liberar al juez del análisis de toda la prueba rendida, de los hechos que estime probados y el razonamiento que conduce a tal estimación ${ }^{3}$.

La interpretación de los tribunales (Cortes de Apelaciones) ha sido, a mi juicio, errática y excesiva en pruritos formales, propios de una lógica formal y legalista excesiva. Se ha señalado a propósito:

"la dictación de las sentencia debe contener las menciones indicadas en el inciso $3^{\circ}$ del artículo 501 del código del ramo, eso es, las contenidas en los números 1, 2, 5, 6 y 7 del artículo 459 del mismo cuerpo legal, donde no se encuentra por lo tanto el análisis de toda la prueba rendida, los hechos que estime probados y el razonamiento que conduce a esa estimación, razón por la cual, el recurso deberá ser rechazado".

Aún más, se entiende que no se infringen las reglas de la sana crítica: "por no ser necesario el requisito establecido en el No 4 del artículo $459^{\prime 4}$ y, por lo mismo, hace improcedente la causal contemplada en el artículo 478 b) del código del ramo, ya que "no puede legalmente fundarse en la omisión de un requisito no previsto por el legislador, ni menos cuando él, eventualmente, no se hubiese cumplido a cabalidad" 5 . En este sentido:

"la falta de fundamentación de la sentencia a la hora de establecer los hechos... más, tratándose de la sentencia que se dicta en un procedimiento monitorio, como aparece del artículo 501 inciso tercero del Código del Trabajo, no requiere contener

\footnotetext{
2 "Que a mayor abundamiento, por tratarse de un procedimiento monitorio aquel en que recato la sentencia en revisión, esta solo debe cumplir con los requisitos señalados en los números 1, 2, 5, 6 y 7 del artículo 459 del Código del Trabajo. De lo que se sigue que no precisa cumplir con lo establecido en los literales 3 y 4 de la dicha disposición legal. El indicado en el último nombrado se refiere al análisis de toda la prueba rendida, los hechos que se estimen probados y el razonamiento que conduce a esa estimación. En consecuencia, al no exigirse en el procedimiento monitorio el análisis de la prueba rendida, los hechos que se estimen probados y el razonamiento que conduce a dicha estimación, el recurso de nulidad en esta clase de procedimiento no puede validar y legalmente fundarse en la causal prevista en la letra b) del artículo 478 del Código del Trabajo". Corte de Apelaciones de Talca, Rol 13-2009, 5 de agosto de 2009.

${ }^{3}$ De manera ilustrativa: "Ha de tenerse presente que el procedimiento monitorio, como el de autos, se rige por las normas del juicio ordinario laboral, con algunas modificaciones, entre las que se encuentra el artículo 501, inciso final, del Código del Trabajo, que señala textualmente: El Juez deberá dictar sentencia al término de la audiencia, la que deberá contener las menciones señaladas en los números 1, 2, 5, 6 y 7 del artículo 459. De lo anterior, se infiere que el juez no está obligado a efectuar una síntesis de los hechos y de las alegaciones de las partes, como tampoco a analizar toda la prueba rendida, sino solo la conducente a dar por establecidos los hechos que estime probados y el razonamiento que sirva de base a dicha conclusión, de acuerdo con las reglas de la sana crítica". Corte de Apelaciones de Punta Arenas, Rol 52008,9 de julio de 2008.

4 Corte de Apelaciones de La Serena, Rol 73-2009, 2 de octubre de 2009. En el mismo sentido ver Corte de Apelaciones de Valparaíso, Rol 566-2009, 18 de enero de 2010. "En todo caso, las causales invocadas de manera conjunta, se sustentan en haberse infringido el artículo $459 \mathrm{~N}^{\circ} 6$ y 4 del Código del Trabajo. Pues bien, el segundo basamento resulta improcedente, si se advierte que la sentencia se dictó en un procedimiento monitorio, respecto del cual el inciso $3^{\circ}$ del artículo 501 del Código del Trabajo nos indica que el fallo deberá contener las menciones señaladas en los números 1, 2, 5, 6 y 7 del artículo 459, con to cual queda fuera el No 4 ".

${ }^{5}$ Corte de Apelaciones de Talca, Rol 3-2009, 14 de septiembre de 2009.
} 
el análisis de la prueba rendida, la determinación de los hechos probados y el razonamiento que conduce a ellos, por lo que también no cabe, sino, desecharla. Por último, la opinión que pueda merecer el diseño legislativo, tanto en lo que dice relación con la posibilidad que el silencio del demandado se considere positivamente, como la no exigencia de motivación en el proceso de valorización de la prueba y establecimiento del factum en el procedimiento monitorio, y el análisis de las razones de ello, también escapan al marco de la causal invocada"6.

Incluso se ha sostenido -como una forma de rechazar recursos de nulidad- que: "conforme al Procedimiento Monitorio que se encuentra reglamentado en los artículos 496 y siguientes del Código Laboral y que faculta al juez de la causa para que, en la sentencia, solo haga una relación de la prueba rendida, en atención a la naturaleza breve y concentrada del mismo"7.

La propuesta elaborada por la jurisprudencia ${ }^{8}$ nos parece que atenta en contra de la finalidad misma de la fundamentación y, también, a los medios de impugnación ${ }^{9}$; que busca resguardar a la partes del proceso y ante al arbitrio judicial. No olvidemos que el

${ }^{6}$ Corte de Apelaciones de Copiapó, Rol 2-2008, 8 de julio de 2008.

7 Corte de Apelaciones de San Miguel, Rol 31-2009, 21 de enero de 2010.

${ }^{8}$ Sin perjuicio del criterio anteriormente propuesto, curiosa nos parece, en una similar situación, el pronunciamiento de la Corte de Apelaciones de Punta Arenas, que sí pone énfasis en la motivación. Corte de Apelaciones de Punta Arenas, Rol 1-2009, 10 de febrero de 2009. "Que antes de analizar las causales de nulidad invocadas por la parte demandante, es necesario tener presente que en el procedimiento monitorio laboral, creado por la reforma, el legislador en el artículo 501 inciso final del Código del Trabajo, prescribe que el juez debe dictar sentencia al término de la audiencia, la que debe contener las menciones señaladas en los números 1, 2, 5, 6 y 7 del artículo 459 del Código mencionado. No se exige un análisis y valoración de la prueba, situación que ha sido advertida por la Sra. Juez del Trabajo en su fallo. Dicha omisión legislativa, ha sido destacada por la doctrina que ha señalado "No puede olvidarse que el derecho a la prueba no solamente se satisface con la posibilidad de presentar la que se estime pertinente, sino que comprende, también, el derecho a que esta sea considerada o descartada razonadamente por el órgano jurisdiccional en la sentencia. Para ello, es necesario tener presente además, que el artículo 432 del Código del Trabajo, ordena aplicar supletoriamente, en primer lugar, las normas del procedimiento de aplicación general contenidas en el párrafo $3^{\circ}$, en el cual se encuentra el artículo 459 del mismo Texto Legal que señala las menciones que debe contener la sentencia, en especial el numeral 3, que se refiere a una síntesis de los hechos y de las alegaciones de las partes; y 4, que se refiere al análisis de la prueba rendida, los hechos que estime probados y el razonamiento que conduce a esta apreciación”. en: ACADEMIA JUDICIAL, Manual del Juicio del Trabajo, Santiago, 2008, p. 129.

S Sumado a lo anterior, confluyen fundamentos que emanan de la propia naturaleza y organización de la judicatura del trabajo. Debido a su estructura funcional, existe una dificultad natural y una mayor posibilidad de error e imprecisión en la determinación de los hechos, en la valoración y apreciaciones subjetivas del material fáctico de la cuestión debatida y de infringir la lógica al aplicar la ley en un caso concreto, puesto que el juez, como persona, se encuentra sujeto a la posibilidad del error, a la falibilidad humana como en todos los campos en que se desempeña como sujeto, haciendo imperiosa la necesidad de la oportunidad para recurrir ante un tribunal distinto de aquel que dictá la sentencia para controlar el fondo de la decisión y la apreciación de las cuestiones de hecho, siendo necesaria la posibilidad real y efectiva de poder recurrir frente a un tribunal superior, sin significar esto el otorgamiento al tribunal de nulidad la misma competencia que un tribunal de instancia. Otro punto a considerar es la falta de debate en sede laboral, debido a la estructura funcional unipersonal de la judicatura en comento, que constata la no existencia de oportunidad y debate de las apreciaciones de hecho, ni una pluralidad de criterios u opiniones que permitan discutir y analizar las distintas visiones frente a un determinada situación, junto con el criterio jurídico a aplicar para la resolución de un caso. Destaca sobre todo la imposibilidad de un control interno entre sus pares a diferencia de lo que ocurre en materia penal, donde la composición colegiada del tribunal oral en lo penal permite una fiscalización entre los mismos sentenciadores que componen el órgano jurisdiccional, evitando los abusos que se pueden cometer en el ejercicio de sus cargos o bien generar la posibilidad real de un autocontrol. 
sustrato de todo medio de impugnación "reside en la falibilidad del juicio humano y en la consiguiente conveniencia de que, por vía de reexamen, las decisiones judiciales se adecuen, en la mayor medida posible, a las exigencias de la justicia" ${ }^{10}$. Tal como lo señala Carnelutti "el peligro de error judicial es como una gran nube que oscurece el cielo del derecho procesal y la previsión de los recursos abre la posibilidad de repararlo" ${ }^{11}$.

De este modo, existe una absoluta desvinculación con elementos que necesariamente forman parte de la noción de debido proceso y que, consecuencialmente, tienen correlación con los elementos olvidados por la jurisprudencia: la motivación y la sana crítica.

\section{LA MOTIVACIÓN Y SU INTRÍNSECA RELACIÓN CON LA SANA CRÍTICA}

En primer lugar, menester es distinguir entre fundamentar una sentencia y motivarla, puesto que una decisión judicial puede ser fundada y no precisamente motivada, presentándose tal confusión, sobre todo, cuando nuestro ordenamiento dispone que toda sentencia deba fundarse en la ley, pero no se hace directa alusión a la motivación.

Fundamentación y motivación, sin perjuicio de ser conceptualizaciones distintas, están estrechamente ligadas. La primera se refiere al derecho aplicable invocado, es decir, a los artículos concretos de una ley que se utilizan para el caso que se pretende fundar, tornándose necesarias la referencia a las normas de derecho positivo que sirven de apoyo al fallo. Así las cosas, el concepto de fundamentación es legal y formal. La segunda guarda relación con la explicación del juez sobre la razón por la cual aplica el derecho de tal o cual forma, esto es, la elucidación concreta con las que fundó sus actos. En otras palabras, apreciar críticamente el material fáctico del pleito, constituido por las cuestiones de hecho y las pruebas que se produzcan en la causa.

La motivación tiene un objetivo más importante: la razón, la justicia y equidad de la decisión. La sentencia ha de estar motivada porque hay que establecer la razonabilidad de la decisión frente a los ciudadanos, por ser una derivación razonada del derecho que existe en un momento dado y el cual no es producto de la voluntad arbitraria del juez. La motivación de una sentencia se constituye entonces por las reglas del pensamiento lógico del sentenciador.

En razón de lo anterior, la motivación resulta exigible en toda sentencia, por lo que esta deberá contener, necesariamente, los antecedentes fácticos y jurídicos, la exigencia de la motivación propiamente tal y la fundamentación de la resolución judicial en cuestión, atendida la finalidad de acercar y someter el actuar del juez a la máxima de las garantías de la actividad jurisdiccional: el debido proceso. De esta manera, la obligación de motivar los fallos se convierte, como diría Falle, en: "la más preciosa de las garantías... ella le protege contra la arbitrariedad, le proporciona la prueba de que su demanda y sus morivos de casación han sido seriamente examinados, y, al mismo tiempo, pone un obstáculo a que el juez pueda substraer su decisión al control de la corte de casación" ${ }^{2}$.

\footnotetext{
${ }^{10}$ Palacios Lino, Enrique, Manual de Derecho Procesal Civil, LexisNexis - Abeledo Perrot, Buenos Aires, 2007, p. 580.

11 Carnelutti, Francesco, Derecho Procesal Penal, México, 1999, p. 174.

12 Paillas, Enrique, El recurso de casación: derecho chileno y comparado, tomo I, ConoSur, Santiago, 1999, p. 178.
} 
El que los fallos deban ser motivados no es un mandato eludible por la judicatura laboral, ya que tal exigencia se consagra en el artículo $459 \mathrm{~N}^{\circ} 3$ y 4 del $\mathrm{CT}^{13}$ constituyéndose tal obligación en un imperativo constitucional, en razón de que el:

“artículo 19 número 3 de la Constitución Política de la República asegura a todas las personas la igual protección de la ley en el ejercicio de sus derechos, preceptuando, asimismo, que a esos efectos el legislador establecerá siempre las garantías de un racional y justo procedimiento; de esta forma establece la necesidad de consagrar mecanismos que aseguren la razonabilidad de las decisiones a través de las cuales se adjudican los derechos de las personas, vale decir, el respeto al principio del debido proceso. Desde un punto de vista dogmático internacional, se entiende que este aspecto del estándar del debido proceso se extiende a la necesidad judicial de estimar argumentativamente las pruebas aportadas por las partes y de exponer las razones que lo lleven a desestimar alguna prueba presentada, de suerte que las partes puedan contar con la evidencia de que la decisión adoptada en definitiva es la consecuencia de la consideración racional de las pruebas presentadas.

En efecto, la sentencia fundada, y particularmente el análisis de la prueba rendida, como asimismo la razonabilidad de dicho análisis, constituye un componente ineludible del derecho al debido proceso, en términos tales que cuando se incumplen tales exigencias no puede sino entenderse afectada la señalada garantía y, si bien, en una primera aproximación pudiera sostenerse que no cualquier quebranto a los requisitos de la sentencia constituye la infracción anotada, lo cierto es que cuando la omisión alcanza, como en el caso que nos ocupa, a gran parte de la prueba rendida, respecto de la cual, como se dijo, el tribunal no argumenta acerca del valor que le otorga, como tampoco respecto de las razones por las cuales la acepta para establecer los hechos de la causa o bien la desestima, no puede sino concluirse que se ha afectado la garantía de la sentencia fundada, como se dijo ínsita en la del debido proceso" 14 .

Como señala Ortell Ramos ${ }^{15}$, el imperativo constitucional de motivar las sentencias satisface, compone y otorga, una ventaja, pues la motivación exige referirse a la ley de la cual se hace aplicación, impidiendo que la decisión se funde en el arbitrio judicial que pueda conducir a la inseguridad jurídica de los ciudadanos. Se suma a ello la mayor perfección en el proceso interno de elaboración de la sentencia, al contribuir también con una función persuasiva o didáctica, ya que "facilita la labor de los órganos jurisdiccionales que conocen de las impugnaciones de la sentencia". De esta forma, se hace indispensable

\footnotetext{
${ }^{13}$ La obligación de motivar las sentencias descansa en el espíritu general de la legislación, consagrándose en diversos textos legales; en el artículo 24 del CC, en el artículo 10 inc. $2^{\circ}$ del COT, en los artículos 160,170 y 785 del CPC, reglamentados en el auto acordado dictado por la Corte Suprema el 30 de septiembre de 1920, en los artículos 500 y 541 No 9 del y a su vez en nuestra normativa supralegal: la constitución en sus artículos 19 No $^{\circ}$ inciso $5^{\circ}$ y 76 . GONZALEZ CASTILlO, José, "La fundamentación de las sentencias y la sana crítica", en: Revista Chilena de Derecho, vol. 33, $N^{\circ} 1$, año 2006, p. 101.

${ }^{14}$ Corte de Apelaciones de Copiapó, Rol 18-2008, 10 de noviembre de 2008.

15 Pereira anabalón, Hugo, "Motivación y fundamentación de las sentencia y debido proceso" en: Gaceta Jurídica, No 142, Santiago.
} 
que los sentenciadores fundamenten y motiven sus decisiones, para procurar evitar las arbitrariedades que se puedan producir en razón del poder que detentan y, consecuentemente, permitir a las partes ejercer efectivamente su derecho a impugnar tales resoluciones, en este caso, mediante el Recurso de Nulidad Laboral.

Si bien el deber de motivar es exigible a todo tipo de sentencia, esta reviste un carácter especial en el sistema de valoración en virtud de la sana crítica, debido a que el sentenciador estará obligado, además de expresar las razones jurídicas, las simplemente lógicas, científicas y de experiencia, a "tomar en especial consideración la multiplicidad, gravedad, precisión concordancia y conexión de las pruebas o antecedentes del proceso que utilice, de manera que el examen conduzca lógicamente a la conducta que convence al sentenciador. Lo que se exige son criterios racionales a fin de evitar arbitrariedades"16.

Precisamente, lo que informa a este sistema de valoración de la prueba es la racionalidad del mismo en su apreciación o persuasión, de manera que la conclusión establecida en la sentencia no sea diametralmente opuesta al mérito de la prueba rendida y los hechos probados. Es por lo que, a los límites naturales de la sana critica, debemos agregar la obligación de fundamentar o más bien motivar la sentencia. Esto permite el ejercicio correcto y adecuado del derecho a impugnar una resolución judicial, al acusar ante el superior jerárquico el desapego de las razones lógicas, de las máximas de experiencias y de los conocimientos científicos, con el objeto de invalidar aquellos errores que desvirtúan una motivación coherente en la sentencia, constituyéndose esta exteriorización del razonamiento en una verdadera garantía para los recurrentes.

Por lo tanto, no basta con que se exprese el razonamiento del juez en la sentencia, de modo que la justificación de "que no se divisa que atente contra el principio de la apreciación de la prueba de la sana crítica pues contiene el análisis de aquella y el razonamiento que la condujo a su estimación" 17 no es suficiente, debido a que tal razonamiento y valoración deben ser conforme con los límites de la sana crítica.

Sumado a lo anterior, la ley exige para la validez de esta causal que la infracción a la valoración de la prueba deba ser manifiesta, entendida como "una infracción notoria, que se detecte de la sola lectura de la sentencia de que se trate" 18 , porque apreciar la prueba de acuerdo con las reglas de la sana critica significa "reconocer la lógica mínima que permita acceder a un conocimiento determinado, no es posible que el sentenciador desconozca las relaciones causales básicas, los hechos evidentes, el hecho notorio, la primacía de la realidad, los actos propios, etc., que representan razonamientos básicos que permiten interpretar o ponderar la prueba rendida en la causa" 19 .

De la misma manera se infringe esta cimentación teórica cuando el sentenciador "no realiza una valoración de todos los medios aportados por las partes, como tampoco realiza una valoración integral de las pruebas... limitándose a extractar solo aspectos parciales de de tales medios de prueba"20, y asimismo, se cumple con las exigencias esta-

\footnotetext{
${ }^{16}$ Corte de Apelaciones de La Serena, Rol No 75-2009, 6 de agosto de 2009.

17 Corte de Apelaciones de Punta Arenas, Rol 14-2009, 2 de abril de 2009.

18 Corte de Apelaciones de Talca, Rol 3-2009, 14 de julio 2009.

19 Corte de Apelaciones de Antofagasta, Rol 8-2009, 2 de julio 2009.

${ }^{20}$ Corte de Apelaciones de la Serena, Rol 75-2009, 3 de agosto de 2009.
} 
blecidas en la ley, de fundamentación y razonabilidad, cuando "se ha analizado pormenorizadamente la totalidad de la prueba rendida, se han dado las razones por las cuales se ha otorgado credibilidad a unas y por qué se desestiman otras, respectivamente, habiendo efectuado el sentenciador un proceso completo de análisis, en que no ha omitido prueba alguna y en que las conclusiones que se vierten en el fallo reproducen el razonamiento utilizado para alcanzarlas"21.

En razón de lo anterior, la única forma de que tales demarcaciones sean respetadas es a través de la obligación de motivar la sentencia, por lo que su argumentación deberá justificar racionalmente su decisión, dejando constancia de esta en la sentencia. Tal imperativo tiene como contenido concreto, en buenas cuentas, permitir la eficacia del control del tribunal a cargo de conocer los recursos de nulidad sobre la razonabilidad en su actuar, facilitando la labor del iudex ad quem que conoce de las impugnaciones de la sentencia.

El valor de la motivación fáctica recae precisamente en la construcción del proceso oral laboral, que por la concentración de este y la inmediación que toma una importancia especial, impone a los jueces un trabajo meticuloso, propio de un artista en la elaboración de la sentencia. Así, la motivación fáctica tiene la importancia de fijar los hechos, lo que se completa al realizar un análisis de toda la prueba ofrecida, señalando los medios de prueba utilizados, estableciendo por qué considera tales en desmedro de otros. Esta exigencia es de vital importancia, ya que permite la reproducción del razonamiento aplicado por el sentenciador al fallar, pues "el control de los errores de derecho por parte del tribunal ad quem solo es posible de realizar sobre una base fáctica correctamente descrita. En ello radica precisamente la justificación de que se eleven a causales de nulidad los vicios de la motivación de la sentencia en cuanto a los hechos"22.

\section{CONCLUSIÓN}

La motivación de la sentencia no puede quedar reservada a la intimidad de la conciencia de los jueces. Debe exponerse en ella el sustento que opera como ligazón racional de la prueba y cuya omisión acarrea la nulidad del ejercicio intelectual de sentenciar por resultar insuficiente. No puede justificarse por la carencia aun de descripción legislativa, ya que tal ausencia se suple por la consagración constitucional de la motivación como elemento subyacente al debido proceso, de modo que resulta inadmisible el subterfugio utilizado por los magistrados a cargo de conocer el recurso de nulidad, el no acogerlo o declararlo inadmisible por tratarse de un procedimiento monitorio que omite la ponderación de la prueba en la sentencia. Tal respuesta es un ejemplo más del formalismo lógico judicial excesivo, como expresión de la deformación de las formas en el proceso.

No es racional, a la luz de un procedimiento racional y justo, desconocer tal obligación al sentenciar y, de ser así, se afecta directamente la posibilidad de revisión de lo fallado por un tribunal superior igualmente imparcial y objetivo, que en buenas cuentas no es otra cosa que la posibilidad de impugnar la sentencia.

${ }^{21}$ Corte de Apelaciones de Copiapo, Rol 20-2008, 21 de noviembre de 2008.

${ }^{22}$ CORTÉs MATCOVICH, Gonzalo Alonso, El recurso de nulidad: doctrina y jurisprudencia, LexisNexis, Santiago, 2006, p. 220. 